\title{
The Utility of Tc-99m MDP Bone Scintigraphy for the Detection of Articular Involvement in Behçet's Disease
}

\author{
Amr Amin ${ }^{*}, 1$ Hanan Darweesh ${ }^{2}$ and Heba Attia ${ }^{2}$ \\ ${ }^{I}$ Nuclear Medicine Department, Faculty of Medicine, Cairo University, Egypt \\ ${ }^{2}$ Rheumatology \& Rehabilitation Department, Faculty of Medicine, Cairo University, Egypt
}

\begin{abstract}
Introduction: Behçet's disease (BD) is a chronic relapsing inflammatory disease. $40-70 \%$ of BD patients display rheumatic features with a $9 \%$ incidence as an initial presentation. However, there are no pathognomonic laboratory tests in $\mathrm{BD}$ and the diagnosis depends on the occurrence and grouping of sufficient clinical manifestations to allow the physician to either suspect, or definitely diagnose the condition. Our aim was to assess the utility of Tc- $99 \mathrm{~m}$ methylene diphosphonate (Tc-99m MDP) bone scintigraphy for the detection of articular involvement in BD patients and its impact on disease activity \& severity scoring.
\end{abstract}

Methods: $25 \mathrm{BD}$ patients diagnosed according to the international study group criteria for BD diagnosis (ISG) $[18 \lambda, 7$, mean age $32.44 \pm 7.78$, disease duration $6.98 \pm 4.61$ year] were included and subjected to selected joint $\mathrm{x}$-ray and bone scintigraphy.

Results: $25 / 25$ was scintigraphically positive for arthritis $[100 \%, 64 \%, 44 \%, 40 \%, 36 \% \& 20 \%$ in wrist, Metacarpophalangeal, proximal interphalangeal (PIPs), distal interphalangeal (DIPs), Knees \& ankles respectively]. 13/25 were clinically negative while scintigraphically positive for arthritis. $11 / 25(44 \%)$ and $8 / 25(32 \%)$ turned from inactive to active $\mathrm{BD}$ and from mild to moderate disease severity, based on their positive hand scintigraphy with treatment modification. 4/25 (16\%) had recurrent oral ulcers with normal laboratory data and only positive hand scintigraphy; with follow-up they met ISG criteria.

Conclusion: skeletal scintigraphy is a simple diagnostic modality with a low radiation burden, when compared to conventional radiology. Hence, when used appropriately in the diagnostic algorithm of $\mathrm{BD}$, bone scintigraphy can be used for detection of early joint involvement, assessment of the extent and activity status with guidance for the selected therapy.

Keywords: Behçet's disease, bone scintigraphy, hand skeletal scintigraphy, vasculitis.

\section{INTRODUCTION}

Behçet's disease (BD) is a relapsing systemic inflammatory condition of unknown etiology that is more prevalent in certain geographical areas and particular ethnic groups $[1,2]$. It is now recognized as a multisystem disease with various organ involvement including skin, mucous membrane, eyes, joints, vessels, gastrointestinal tract and nervous system [3]. However, since vascular manifestations are common in this disease, it is regarded as vasculitis. The predominant histopathology in the inflamed tissues is infiltration of lymphocytes and monocytes through small veins walls without microscopic changes. Thrombophilia or thrombophlebitis involving small and large veins is also common whereas arteritis is rare. In this regard BD is unique when compared with other vasculitides [4].

There are no pathognomonic laboratory tests in BD and diagnosis depends on the occurrence and grouping of sufficient manifestations to either suspect, or definitely diagnoses, the condition [5]. Several clinical criteria have been developed to assist the diagnosis. The older O'Duffy

*Address correspondence to this author at the Nuclear Medicine, Faculty of Medicine, Cairo University, Egypt; Tel: +20101648583;

E-mail: amramin67@gmail.com criteria required oral aphthae, plus at least two of the followings: genital aphthae; synovitis; posterior uveitis; positive skin pathergy test (SPT); or meningoencephalitis, in the absence of inflammatory bowel disease or other collagen vascular disease [6]. New international study group criteria (ISG) for BD diagnosis was published [7], requiring the presence of recurrent oral aphthae (three times/year) plus $2 / 4$ criteria with no other systemic diseases (Recurrent genital ulceration, Eye involvement, Skin lesions and Positive SPT).

Although, arthritis or arthralgias are not included in ISG [7], both are among the most frequent manifestations of BD [8]. Articular involvement was reported in $5-76 \%$ of $\mathrm{BD}$ patients [9] being intermittent, self-limiting, non-erosive, symmetric or asymmetric oligoarthritis, although polyarticular and monoarticular forms are also seen [10]. Arthritis or arthralgias are in the items of the BD activity and severity scores (Aydintug and Yosipovitch methods) [11, 12].

Although joint manifestations have become a wellknown part of the spectrum of multisystemic involvement in $\mathrm{BD}$, previous descriptions have been limited to conventional radiographic findings. These findings have been described as being normal or showing mild abnormalities consisting of nonspecific finding such as osteoporosis, and soft-tissue 
swelling with joint-space narrowing and marginal erosions only rarely [13].

The nuclear medicine role in rheumatology is evolving continuously since 50 years and currently, we have scintigraphic procedures and radiopharmaceuticals to image inflammation early with minimum radiation and cost burden $[10,14]$. Tc-99m methylene diphosphonate (Tc-99m MDP) bone scintigraphy is a non- invasive method which can detect early sub-clinical arthritis in BD with no or mild symptoms and normal radiography $[3,15,16]$.

In treatment guidelines of $\mathrm{BD}$ corticosteroids are included [17]; in the absence of disease activity steroids are injurious for the vascular endothelium while it is advantageous in active BD [18], thus the evaluation of disease activity is of great importance.

This study was conducted to evaluate the utility of Tc$99 \mathrm{~m}-\mathrm{MDP}$ bone scintigraphy in the detection of articular involvement in BD patients and to correlate it with clinical manifestations, disease activity and severity.

\section{PATIENTS AND METHODS}

$25 \mathrm{BD}$ patients diagnosed according to the ISG [7] were included in this study. Our data base included clinical data, SPT and laboratory results [Leukocytes count, hemoglobin $(\mathrm{Hb})$, erythrocyte sedimentation rate (ESR) \& C-reactive protein (CRP)] together with radiological and skeletal scintigraphic results. The patient was considered to have active disease state when at least two of the following manifestations were present; oral or genital ulcers, eye or skin or vascular lesions, arthritis, pulmonary and CNS involvement (Aydintug method) [11]. Severity score was calculated as the sum of " $1,2,3$ points" for each of the mild, moderate and sever disease manifestations respectively (Yosipovitch scoring model) [12].

\section{Plain Radiography}

Radiological joint survey was performed in the A-P and lateral views for all joints except for the hands where A-P and P-A views were done and specific views for sacroiliac joints. Joints were scored according to Larsen score: $0=$ normal; $1=$ soft tissue swelling and/or joint space narrowing/subchondral osteoporosis; $2=$ erosions with destruction of the joint surface (DJS) $25 \%$; 3 = DJS 26-50\%; $4=$ DJS 51-75\%; $5=$ DJS $>75 \%$ [19].

\section{Bone Scintigraphy}

Skeletal scintigraphy was performed only in the late post 2-3 hours phase following intravenous injection of 555-740 $\mathrm{MBq}$ of Tc-99m-MDP, using a dual headed rectangular, large field-of-view gamma camera (Phillips- vertex plus) mounted with a low-energy, high-resolution collimator with a $20 \%$ energy window setting centered at $140 \mathrm{keV}$. An experienced physician interpreted the scans. Hand scintigraphic interpretation was done using the four point Yurtkuran scale method: $0=$ none, $1=$ mild, $2=$ moderate, $3=$ severe [20].

\section{Statistical Method}

All data were analyzed and interpreted using a statistical package for social science (SPSS, version 11). Descriptive Statistics were represented as means and standard deviation, as well as frequencies and percentages. Contingency coefficient " $\mathrm{r}$ " was used as an index to describe the strength of the association between any two variables. The cross tabulation was used to detect the correlation between the variables. To test the significant difference between hand plain $\mathrm{x}$-ray and hand bone scintigraphy, we use the non parametric test (Wilcoxon Signed Ranks Test). P value of $<0.05$ was judged to be statistically significant.

\section{RESULTS}

The study group included 18/25 (72\%) and 7/25 (28\%) $\widehat{O} \&$ + respectively. Their mean age was $32.44 \pm 7.78$ year with a mean disease duration $6.98 \pm 4.61$ year. Their laboratory data are shown in Table 1, while the clinical manifestations in the last month prior to the study time were detailed in Table 2 . The radiological survey showed Larsen's score $0(6 / 25)$ and $1(19 / 25)$ BD patients (Table 3$)$.

Table 1. Laboratory Data of the Study Population (n. 25)

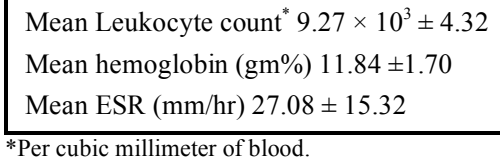

Table 2. Clinical Data of BD Patients and the Used Drugs ( $n$. 25)

\begin{tabular}{|c|c|c|}
\hline Manifestations in the Last Month & $\begin{array}{c}\text { Number of } \\
\text { Patients (No.) }\end{array}$ & $\begin{array}{c}\text { Percentage } \\
\%\end{array}$ \\
\hline Oral ulcers & 14 & 56 \\
\hline Genital ulcers & 5 & 20 \\
\hline Skin lesions & 6 & 24 \\
\hline Eye manifestations & 11 & 44 \\
\hline Joint manifestations & $12^{*}$ & 48 \\
\hline Major vessels & 8 & 32 \\
\hline CNS manifestations & 1 & 4 \\
\hline Recent deep venous thrombosis (DVT) & 3 & 12 \\
\hline Positive Skin Pathergy Test (SPT) & 4 & 16 \\
\hline Medical Treatment & & \\
\hline - Steroids & 3 & 12 \\
\hline $\begin{array}{l}\text { - } \begin{array}{l}\text { Steroids and other types of } \\
\text { medications }\end{array}\end{array}$ & 14 & 56 \\
\hline $\begin{array}{l}\text { - Other types of medications }{ }^{\dagger} \\
\text { without steroids }\end{array}$ & 8 & 32 \\
\hline
\end{tabular}

Bone scintigraphy demonstrated articular involvement in the wrists of all $\mathrm{BD}$ patients. The frequency for other involved sites is detailed in Table 4. 4/25 (16\%) had recurrent oral ulcers with normal laboratory data and only positive hand scintigraphy; with follow-up they met ISG criteria. The analysis of hand scintigraphy based on the 4 point scale method showed mainly the 2 point scale in the wrist and MCPs positive cases while 1 point scale in the PIPs and DIPs [20].

There was no significant correlation between the radiologically and scintigraphically based arthritis in BD patients with age, sex and disease duration. Regarding the 
disease activity; $14 / 25$ were in clinically active disease state and the remainders $(11 / 25)$ were clinically inactive; however bone scan was positive for hand arthritis in each of them thus turned them to the category of active disease state. As regards the clinical disease severity score; 10/25, 7/25 and $8 / 25$ patients were classified into mild, moderate and severe scores respectively and based on the radiological and scintigraphic findings $5 / 10(50 \%)$ and $8 / 10(80 \%)$ were upgraded from mild to moderate categories respectively. Also, a statistically significant positive correlation was found between ESR and scintigraphically detected hand arthritis $(r=0.4, p$ 0.03). Using Wilcoxon Signed Ranks Test, there was a highly significant difference between hand $\mathrm{x}$-ray and hand bone scan $(Z=4.284, P$ 0.001) (Fig. 1).

Table 3. Radiological Findings of Abnormal X-Rays in BD Patients (n. 19)

\begin{tabular}{|c|c|c|}
\hline Plain X-Ray Findings & No & $\mathbf{\%}$ \\
\hline \hline Juxta-articular osteopenia $^{*}$ & 19 & 100 \\
Narrowing in PIPs $^{*}$ & 4 & 21 \\
Reduced CMC $^{\dagger}$ & 1 & 5.3 \\
Reduced IC $^{\ddagger}$ bone spaces & 1 & 5.3 \\
${\text { Cyst in } 3^{\text {rd }} \text { MCP }^{\S}}_{\text {Narrowing in SIJ }}$ & 1 & 5.3 \\
\hline
\end{tabular}

*PIP Proximal interphalangeal, ${ }^{\dagger} \mathrm{CMC}$ Carpometacarpal joints, ${ }^{\ddagger}$ Intercarpal, ${ }^{8} \mathrm{MCP}$ Metacarpophalangeal, " Sacroiliac joint.

\section{DISCUSSION}

Multiple systemic associations of $\mathrm{BD}$ have been recognized including articular, vascular, gastrointestinal, cardiopulmonary and neurological involvement [3]. However the clinical characteristics of patients and the frequency of organ involvement is different from an area to another, as elicited from the different BD studies along the silk road lands as Turkey, North of Africa (Egypt, Tunisia, Morocco), and East of Asia as China, Japan and Korea, which suggest that geographic, environmental and genetic factors are of importance in the pathogenesis of the disease and its sequels [21]. Regarding sex ratio; our study population ( $\delta$ : + ratio 2.1:1) was in concordance with the world wide reports. Reported examples are: $(188 \widehat{\delta} \& 72$ + $)$ [22], and (128/183 $\$$ \& 54/183 +) [23].

Table 4. Frequency of Scintigraphic Articular Involvement in BD Patients (n.25)

\begin{tabular}{|c|c|c|}
\hline Region & No. & $\%$ \\
\hline Wrist & 25 & 100 \\
\hline $\mathrm{MCPs}^{*}$ & 16 & 64 \\
\hline $\operatorname{PIPs}^{\dagger}$ & 11 & 44 \\
\hline DIPs & 10 & 40 \\
\hline Knee & 9 & 36 \\
\hline Ankle & 5 & 20 \\
\hline SIJs $^{\S}$ & 4 & 16 \\
\hline Shoulder & 1 & 4 \\
\hline Elbow & 1 & 4 \\
\hline MTP ${ }^{\|}$ & 1 & 4 \\
\hline
\end{tabular}

Up to $50 \%$ BD patients display rheumatic features including arthritis being intermittent, self-limiting, nonerosive and non-deforming usually monoarticular or symmetrical oligoarticular subacute arthritis [10]. Articular involvement in BD patients was aimed in this study using clinical, skeletal scintigraphy and radiological joint survey. $5-97 \%$ clinically based arthritis in BD was previously reported [3, 20, 24-26]. In our study 12/25 (48\%) had clinically evident arthritis and this concurs with the incidence (about 50\%) in the Mediterranean (Turkey, Egypt and Lebanon), and North Africans (Tunisia and Morocco) [23, 26-28], however in Asia (Oman) [29] or far Asians (Korea) $[24,26]$, this incidence shoots up to $75-97 \%$. 2/25 $(8 \%)$ of our cases had rheumatoid-like hand findings in the form of swelling of PIPs and MCPs. A Turkish study reported similar findings in $28.1 \%$ of their patients [20]. Although not uncommon to be found among BD, we must consider that $\mathrm{BD}$ is possible to present with severe arthritis though it is usually non-erosive.

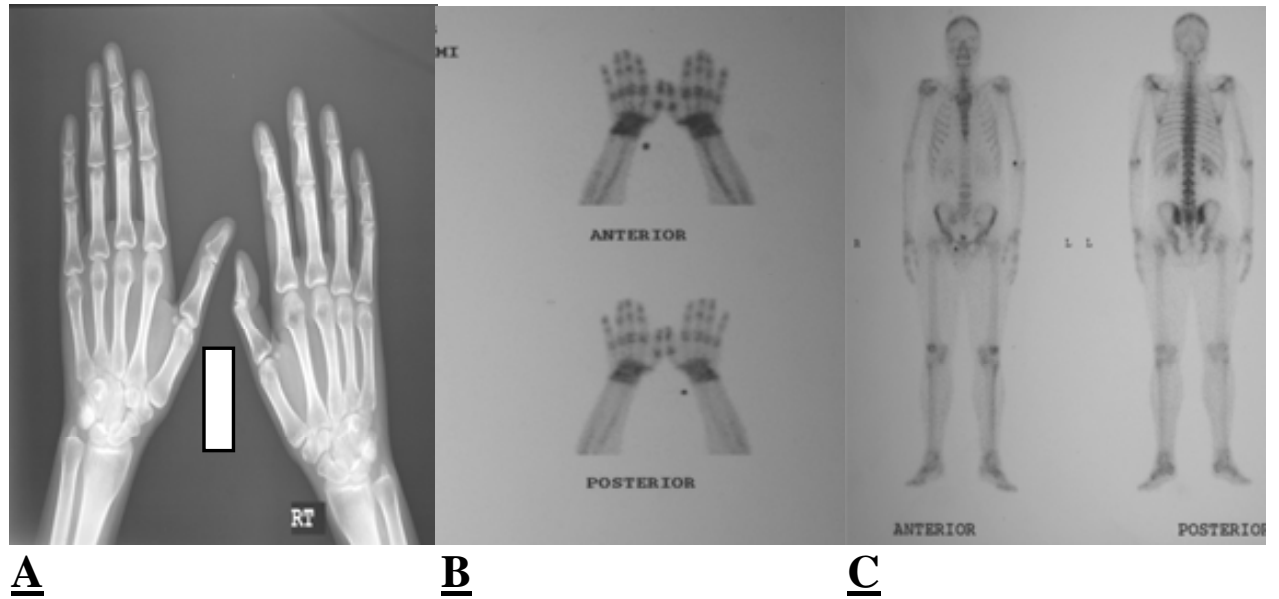

Fig. (1). Radiographic and scintigraphic features of a BD patient. (A) Plain x-ray of hands showing juxta-articular osteopenia. (B) Bone scans of both hands showing increased uptake in bilateral wrists, Metacarpophalangeal \& proximal interphalangeal joints. (C) Whole body scans with no other articular abnormalities. 
Skin lesions and positive SPT were found in $24 \%$ \& $16 \%$ respectively compared to $16 \%$ in a North African study [23], others reported higher positive SPT (51\% \& 61.4\%) [20,30]. These differences are attributable to geographic, environmental and genetic factors variability [21].

The involved joints in our study were detailed in Table $\mathbf{4}$ with the wrist and hand joints $(100 \%)$, knee $(36 \%)$, ankle $(20 \%)$, and SIJ (16\%) (Table 4), being 58.4\% oligoarticular, $33.3 \%$ monoarticular and $8.3 \%$ polyarticular. In previous studies sacroiliitis was found in less than $25 \%$ of BD patients $[3,24]$, so it should be considered in those patients with persistent low back pain. As mentioned earlier, clinically the knees (about 58\%) and wrists (approximately 50\%) were the most frequently affected sites, mostly oligoarticular [28, 3133]. While the scintigraphically evidenced wrist arthritis reaches up to $75 \%[3,20]$ deducing the higher sensitivity of scintigraphy.

$12 / 25(48 \%)$ of BD patients had clinically based arthritis while the radiologically and scintigraphically detected arthritis were 19/25 (76\%) \& 25/25 (100\%) respectively. This keeps with Sahin et al, who reported 25\% \& 84.4\% clinically and scintigraphically based arthritis respectively [3]. These reports are in agreement with the elicited significant difference between the radiologically and scintigraphically based arthritis (Z-value $=4.284$, Pvalue $=0.001$ ) denoting that the hand bone scan was more comprehensive than hand $\mathrm{x}$-ray. Also, radiological findings are non specific and we cannot rely on them for evaluating active joint arthritis [13]. The higher associated radiation dose compared to bone scintigraphy is another limiting factor. Using the 4 point scale for hand scintigraphy; $24 \%$ mild, $60 \%$ moderate and $16 \%$ high grade scores were detected in concordance with Yurtkuran et al. study, [20] where $29.2 \%, 62.5 \%$ and $8.3 \%$ had mild, moderate and high grade scores respectively.

The impact of the scintigraphically detected arthritis on the clinically estimated activity \& severity scores was evaluated as a main goal in our study.11/25 BD were in the inactive clinical disease state with the Aydintug method. Based on scintigraphy all the 11 patients were found to have arthritis, mainly hands, suggesting the upgrading of their clinical disease state. Using the Yosipovitch method, 10/25, $7 / 25 \& 8 / 25$ BD patients had mild, moderate and severe clinical disease severity scores respectively. Also, bone scan was positive for arthritis in $8 / 10(80 \%)$ of those of mild severity scores, thus they were promoted to the moderate severity score with the subsequent influence on their therapy selection. This is supported by the statistically significant positive correlation that was found between ESR and scintigraphically detected hand arthritis $(r=0.4, p 0.03)$. Elevated ESR was reported to associate exacerbations of arthritis in up to $80 \%$ of BD patients $[17,31]$. We could consider ESR as a lab item in BD clinical portrayal regarding disease activity and follow-up. Our suggested impact of scintigraphy on estimating disease activity and severity is of high clinical relevance considering the influence on the therapy selection and corticosteroids usage, as the latter have a bipolar effect on vascular endothelium in $\mathrm{BD}$ depending on the inflammatory state, being determined by the activity and severity scores. In active exacerbations they are beneficial in reversing vascular endothelial dysfunction, but in remissions, they are deleterious for the vascular endothelium [34]. Moreover, there are some reports about monitoring treatment response in BD active arthritis by skeletal scintigraphy [35], this may reflect that scintigraphy could be an an objective parameter in assessing BD activity \& severity. We noticed that $4 / 25(16 \%)$ had recurrent oral ulcers with normal laboratory data and only positive hand scintigraphy; with follow-up they met ISG criteria. It was previously reported that the immunohistochemical analysis of the synovial tissue samples of newly diagnosed BD showed neutrophilic infiltration essentially in the intimal lining layer with CD4 and CD8 T-lymphocytes subsets and documented presence of interferon gamma (INF- $\gamma$ ), Tumor necrosis factor alpha (TNF- $\alpha$ ), interleukin (IL)-2, IL-4, IL-6 and IL-17 and other cytotoxic effectors (perforin) in the synovial fluid aspirates [36]. Our group noticed that the latter is similar to the currently proposed immunopathogenic model in BD [37]. Therefore, we suggest using bone scintigraphy as a reinforcing element in the early diagnosis of BD.

\section{CONCLUSION}

Skeletal scintigraphy is a simple diagnostic modality with a low radiation burden, when compared to conventional radiology. Hence when used appropriately in the diagnostic algorithm of $\mathrm{BD}$, scintigraphy could be used for the detection of clinically quiescent arthritis and assessment of disease activity and severity states.

\section{ABBREVIATIONS}

$\begin{array}{ll}\mathrm{BD} & =\text { Behçet's disease } \\ \mathrm{Tc}-99 \mathrm{~m} \mathrm{MDP} & =\text { Tc-99m methylene diphosphonate } \\ \mathrm{ISG} & =\text { International study group criteria for BD } \\ \mathrm{SPT} & =\text { Skin pathergy test } \\ \mathrm{A}-\mathrm{P} & =\text { Antero-posterior } \\ \mathrm{P}-\mathrm{A} & =\text { Postro-anterior }\end{array}$

\section{REFERENCES}

[1] Yazici H. Behçet's syndrome. In Oxford Textbook of rheumatology Edited by: Madisson PJ, Isenberg DA, Glass DN. Oxford Medical Publications, London, England; 1993; pp. 884889.

[2] Gul A. Behçet's disease: an update on pathogenesis. Clin Exp Rheumatol 2001; 19 (Suppl 24): S6-S12.

[3] Sahin M, Yildiz M, Tunc SE, et al. The usefulness of Tc-99mMDP bone scintigraphy in detection of articular involvement of Behçet's disease. Ann Nucl Med 2006; 20: 649-653.

[4] Hirohata S, Kikuchi H. Behçet's disease. Arthritis Res Ther 2003; 5:139- 146.

[5] Barnes CG. Treatment of Behçet's syndrome. Rheumatology (Oxford). 2006; 45:245-247

[6] O'Duffy JD. Suggested criteria for diagnosis of Behçet's disease. J Rheumatol 1974; 1(1): 18.

[7] Criteria for diagnosis of Behçet's disease. International Study Group (ISG) for Behçet's disease Lancet 1990; 335(8697): 107880.

[8] Yurdakul S, Yazici H, Tuzun Y, et al. The arthritis of Behçet's disease: a prospective study. Ann Rheum Dis 1983; 42:505-15.

[9] Al-Mutawa SA, Hegab SM. Behçet's disease. Clin Exp Med 2004; 4:103-31.

[10] Kumar AVS, Kumar PG, Shankar S. Role of nuclear medicine in evaluation and management of joint disease. Indian J Rheumatol 2009; 4: 61-68.

[11] Aydintug AO, Tokguz G, Ozoran K, et al. Elevated levels of soluble intracellular adhesion molecule-1 correlate with disease activity in BD. Rheumatol Int 1995; 15: 75-78. 
[12] Yosipovitch G, Shohat B, Bshara J, et al. Elevated serum interleukin-1 receptor and interleukin-1B in patients with Behçet's disease: correlation with disease activity and severity. Isr J Med Sci 1995; $31: 245-8$.

[13] Choi JA, Kim JE, Koh SH, et al. Arthropathy in Behçet's disease: MR Imaging finding in two cases. Radiology 2003; 226: 387-9.

[14] Rogers MJ, Gordon S, Benford HL, et al. Cellular and molecular mechanisms of action of biphosphonates. Cancer 2000;88(12 Suppl):2961-78

[15] Yapar Z, Kibar M, Soy M, et al. Osteonecrosis in Behçet's disease seen on bone scintigraphy. Clin Nucl Med 2001; 26:267-268.

[16] Prakash S, Gopinath PG, Bhargava S, et al. Evaluation of quantitative sacroiliac scintigraphy for the early detection of sacroiliitis. Eur J Nucl Med 1983; 8:531-534.

[17] Yurdakul S and Yazici H. Behçet's syndrome. Clin Rheumatol 2008; 5:793-809.

[18] Protogerou AD, Sfikakis PP, Stamatelopoulos KS, et al. Interrelated modulation of endothelial function in Behcet's disease by clinical activity and corticosteroid treatment. Arthritis Res Ther 2007; 9:R90.

[19] Larsen A. How to apply Larsen score in evaluating radiographs of rheumatoid arthritis in long-term studies? J Rheumatol 1995; 22: 1974-5.

[20] Yurtkuran M, Yurtkuran M, Alp A, et al. Hand involvement in Behçet's disease. Joint Bone Spine 2006; 73: 679-683.

[21] Shahram F, Nadji A, Jamshidi AR, et al. Behçet's disease in Iran, analysis of 5059 cases. Arch Iranian Med 2004; 7: 9 -14.

[22] Houman MH, Neffati H, Braham A, et al. Behçet's disease in Tunisia. Demographic, clinical and genetic aspects in 260 patients. Clin Exp Rheumatol 2007; 25:S58-64.

[23] El-Maghraoui AE, Tabache F, Bezza A, et al. A controlled study of sacroiliitis in Behçet's disease. Clin Rheumatol 2001; 20:189-91.

[24] Han EC, Oh SH, Bang D. Evaluation of the articular involvement of Behçet's disease via bone scintigraphy. Korean J Dermatol 2009 47(1):30-35.

[25] Tănăseanu S, Tănăseanu C, Pompilian V, et al. Clinical particularities in a Romanian series of Behçet's disease patients. Rom J Intern Med 2003; 41(1): 41-51.
[26] Park JH. Clinical analysis of Behçet's disease: arthritic manifestation in Behçet's disease may present as seronegative rheumatoid arthritis or palindromic rheumatism. Korean J Intern Med 1999; 14: 66-72.

[27] Taarit CB, Ben Turki S and Ben Maiz H. Rheumatologic manifestation of Behçet's disease: report of 309 cases. Rev Med Intern 2001; 22: 1049-55.

[28] Ait Badi MA, Zyani M, Kaddouri S, et al. Skeletal manifestations in Behçet's disease. A report of 79 cases. Rev Med Intern 2008; 29 . 277-82.

[29] El-Ageb EM, AL-Maini MH, Al-Shukaily, et al. Clinical features of Behçet's disease in patients in the Sultanate of Oman; the significance of antiphospholipid antibodies? Rheumatol Int 2002; 21: $176-81$.

[30] B'chir Hamzaoui S, Harmel A, Bouslama K, et al. Behçet's disease in Tunisia. Clinical study of 519 cases. Rev Med Interne 2006; 27: $742-50$

[31] Cheng YK, Thong BY, Chng HH. Behcet's disease: experience in a tertiary rheumatology centre in Singapore and a review of the literature. Ann Acad Med Singapore 2004; 33: 510-4.

[32] Yang IH, Han CD, Oh HC, et al. Behçet's arthritis. J Korean Orthop Assoc 2008; 43: 220-226.

[33] Gur A, Sarac AJ, Burkan YK, et al. Arthropathy, quality of life, depression, and anxiety in Behcet's disease: relationship between arthritis and these factors. Clin Rheumatol. 2006; 25:524-31.

[34] Espinosa G, Font J, Tassies D, et al. Vascular involvement in Behçet's disease; relation with thrombophilic factors, coagulation activation, and thrombomodulin. Am J Med 2002; 112:37-43.

[35] Vaseem US and Robert EO. Benign bone disease. In: Martin PS, Edward CR, James AP, Frans J, Wackers TH, Alexander G eds. Diagnostic Nuclear Medicine. Vol 1, $4^{\text {th }}$ ed. Lippincott Williams and Wilkins Company; Philadelphia 2003; pp. 429-47.

[36] Canete JD, Celis R, Noordenbos T, Moll C, et al. Distinct synovial immunopathology in Behçet's disease and psoriatic arthritis. Arthritis Res Ther 2009; 11: R17.

[37] Freysdottir J, Lau S, Fortune F. Gammadelta T cells in Behçet's disease (BD) and recurrent aphthous stomatitis (RAS). Clin Exp Immunol 1999; 118: 451-457.

(C) Amin et al.; Licensee Bentham Open.

This is an open access article licensed under the terms of the Creative Commons Attribution Non-Commercial License (http://creativecommons.org/licenses/by-nc/ $3.0 /$ ) which permits unrestricted, non-commercial use, distribution and reproduction in any medium, provided the work is properly cited. 